\title{
Identification of Proton Populations in Cherts as Natural Analogues of Pure Silica Materials by Means of Low Field NMR
}

\author{
Artur T. Krzyżak ${ }^{1, *},+$, Weronika Mazur ${ }^{1,+}$, Jacek Matyszkiewicz ${ }^{2,}$, Alicja Kochman $^{2,}{ }^{\dagger}$
}

${ }^{1}$ Department of Fossil Fuels, Faculty of Geology, Geophysics and Environmental Protection, AGH University of Science and Technology

${ }^{2}$ Department of Environmental Analysis, Geological Mapping and Economic Geology, Faculty of Geology, Geophysics and Environmental Protection, AGH University of Science and Technology

\section{Supporting Information}

\section{Table of Contents}

\section{Sections}

1. Principal Component Analysis- theory and interpretation method

2. Data......

\section{Tables}

Coordinates of peaks from $1 \mathrm{D}^{-\mathrm{T}_{1}}$ distributions

Original variables that were considered in the PCA

\section{Figures}

Pore Size Distribution (PSD) determined from 1D-T2 distributions of saturated samples, assuming that they are composed of $100 \% \mathrm{SiO}_{2}$ 


\section{Principal Component Analysis- theory and interpretation method}

Principal Component Analysis (PCA) is a procedure that transforms observed variables, called original variables, into new variables called Principal Components (PCs). PCs are uncorrelated and are linear combinations of original variables:

$$
P C_{i}=\sum_{j=1}^{n} a_{i j} X_{j}
$$

where

$P C_{i}-i$-th PC,

$n-$ number of original variables,

$X_{j}-j$-th original variable,

$a_{i j}-j$-th coefficient of $i$-th PC (weights of original variables comprising PC).

Each PC explains a part of the variance of original variables. Therefore, PCA relies on covariance or correlation that are measures of a variance. In order to determine PCs, the following eigenproblem needs to be solved:

$$
(M-\lambda I) a=0
$$

where

$\lambda$ - eigenvalues matrix (variances of linear combinations (1)),

$M$ - matrix of covariance or correlation between original variables,

$I$ - identity matrix,

$a$ - eigenvectors matrix (matrix composed of vectors $a_{i}$, which components are weights of $\left.X_{j}\right)$.

Each PC, $P C_{i}$, is then described by the eigenvalue $\lambda_{i}$, the eigenvector $a_{i}$, factor loadings, variable contributions.

Eigenvalue informs us about the percentage of the total variance of original variables. The first PC always explains the highest part of the total variance, and the consecutive PCs 
explains the decreasing amount of the variance. For a given $P C_{i}$ a percentage variance explained by it can be calculated as

$$
\frac{\lambda_{i}}{\sum_{i=1}^{n} \lambda_{i}} \cdot 100 \%
$$

The cumulated variance explained by PCs can also be calculated.

Eigenvectors reflect the influence of original variables on a given PC. The sign of a eigenvector component $a_{i j}$ indicates whether the PC is positively or negatively influenced by $j$-th original variable.

Factor loading of an original variable reflects the part of a variance of $P C_{i}$ that is explained by this variable. Variable contributions indicate the percentage of $P C_{i}$ variability that can be explained by the variability of particular original variables. The higher the contribution of an original variable, the more the $P C_{i}$ depends on it.

The results of PCA can be interpreted graphically. In the article, all of the abovementioned information is presented in the form of biplots, i.e. graphs that show two series- vector and scatter plot.

In the vector plot, each vector's end represents the factor loading of a given original variable, while its length indicates to which extent two PCs represent the original variable (it is well represented when the vector touches or almost touches the unitary circle reflecting correlation between variable and PC). The sign of a coordinate of the end of a vector informs us whether the original variable is directly (positive coordinate) or inversely (negative coordinate) correlated with PC. The angle between two vectors indicates the strength of the correlation between the two original variables:

a) $0-90^{\circ}-$ the smaller the angle, the more positively correlated,

b) $90^{\circ}$ - they are uncorrelated,

c) $90^{\circ}-180^{\circ}$ - the higher the angle, the more negatively correlated.

In the scatter plot, each point represents a sample and its coordinates are standardized values. Thus, positive coordinates indicate values higher than a mean value of PC, while negative coordinates are lower values. The distance between two points informs us about the similarity of the two corresponding samples, which is higher when the points lie closer to each other. The orthogonal projection of a point onto the direction of a vector can be interpreted 
similarly, but the analysis concerns original variables- values placed far in the direction of a vector are higher than mean original variable represented by this vector, while values far in the opposite direction, i.e. on the extension of a vector, are lower.

\section{Data}

Table S1. Coordinates of peaks from 1D- $T_{1}$ distributions shown in the Figure 2B), 2D), 2F), $2 \mathrm{H})$. Peaks were located in the 5 regions, for which $T_{1}$ was consecutively one order larger, and numbered from 1 to 5 , from the left to the right side of the distributions. In addition to the number, the peaks have a letter that corresponds to the saturation state for which the distributions were obtained: Dry, d, Native, $n$, Saturated, s and for differential data of Saturated and Dry samples, sd. The last column consists of $T_{1}$ logarythmic means $\left(T_{1} l m\right)$ calculated from $1 \mathrm{D}-T_{1}$ distributions for the samples in each saturation state.

\begin{tabular}{|c|c|c|c|c|c|c|c|c|}
\hline \multirow[t]{2}{*}{$\begin{array}{c}\text { Saturation } \\
\text { state }\end{array}$} & \multirow[t]{3}{*}{ Sample } & \multicolumn{6}{|c|}{$T_{1}$ relaxation time $(\mathrm{ms})$} & \multirow{2}{*}{$\begin{array}{l}\text { Logarythmic } \\
\text { Mean, } \\
T_{1} \operatorname{lm}(\mathrm{ms})\end{array}$} \\
\hline & & \multicolumn{5}{|c|}{ Peak number } & & \\
\hline \multirow{5}{*}{ خ্ّ } & & D1 & D2 & D3 & D4 & D5 & D6 & \\
\hline & AK1 & & & 1.8 & 29.3 & 117.6 & 310.8 & 73.3 \\
\hline & AK2 & & & 1.4 & 27.4 & 117.6 & 439.8 & 55.8 \\
\hline & AK3 & & & 1.7 & 31.4 & 219.6 & & 33.7 \\
\hline & AK4 & & & 1.0 & 18.0 & 155.2 & & 35.3 \\
\hline \multirow{5}{*}{ 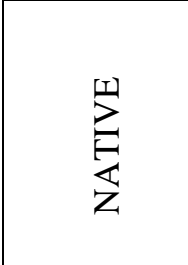 } & & N1 & $\mathbf{N 2}$ & N3 & N4 & N5 & N6 & \\
\hline & AK1 & & & 2.1 & 20.7 & & 166.4 & 50.7 \\
\hline & AK2 & & & 1.6 & 22.2 & & 155.2 & 19.1 \\
\hline & AK3 & & & 2.0 & 29.3 & & 252.4 & 19.8 \\
\hline & AK4 & & & 1.3 & 11.1 & 72.3 & 235.4 & 29.5 \\
\hline \multirow{5}{*}{ 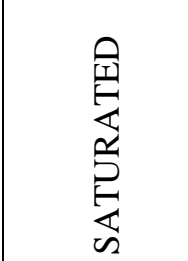 } & & S1 & $\mathbf{S 2}$ & S3 & S4 & S5 & S6 & \\
\hline & AK1 & 0.020 & 0.30 & 1.5 & 27.4 & 178.3 & & 23.9 \\
\hline & AK2 & 0.026 & 0.52 & & 14.6 & 135.1 & 580.5 & 15.8 \\
\hline & AK3 & 0.040 & 0.98 & 1.5 & 14.6 & 219.6 & & 9.6 \\
\hline & AK4 & 0.025 & 0.64 & & 11.9 & 102.3 & 178.3 & 9.4 \\
\hline \multirow{5}{*}{ 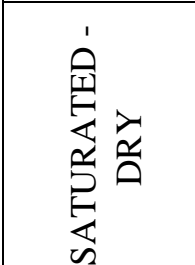 } & & SD1 & SD2 & SD3 & SD4 & SD5 & SD6 & \\
\hline & AK1 & & 0.30 & 2.8 & 27.4 & 166.4 & & 60.8 \\
\hline & AK2 & 0.040 & 0.74 & & 11.9 & & & 3.1 \\
\hline & AK3 & 0.037 & & 2.6 & 13.7 & & & 4.6 \\
\hline & AK4 & 0.020 & 1.1 & 4.2 & 36.1 & & & 2.8 \\
\hline
\end{tabular}

Table S2. Original variables that were considered in the PCA divided into coloristic groups presented in Figure 10. Additionally, their percentage contribution into two considered 
Principal Components is shown. Original variables are $T_{1}$ and $T_{2}$ relaxation times of peaks numbered $\mathrm{Xi}$, where $\mathrm{X}=\mathrm{D}, \mathrm{N}, \mathrm{S}, \mathrm{SD}$ means the saturation state (Dry, Native, Saturated or Saturated-Dry, respectively) and $\mathrm{i}=1,2,3,4,5,6$ is a number of a peak beginning from the left side of a distribution, as well as their integrals $I_{k}$, where $\mathrm{k}=1,2$ and indicates the $1 \mathrm{D}-T_{1}$ and $1 \mathrm{D}-T_{2}$ distribution, respectively.

\begin{tabular}{|c|c|c|c|c|}
\hline Saturation state & Coloristic group & $\begin{array}{c}\text { Original } \\
\text { Variable }\end{array}$ & $\begin{array}{l}\text { Contribution to } \\
\text { PC } 1(\%)\end{array}$ & $\begin{array}{l}\text { Contribution to } \\
\text { PC } 2(\%)\end{array}$ \\
\hline \multirow{19}{*}{ Dry } & \multirow{6}{*}{ Green } & $T_{2}$ of D2 & 6.01 & 4.77 \\
\hline & & $I_{2}$ of $\mathrm{D} 2$ & 8.74 & 0.05 \\
\hline & & $I_{1}$ of $\mathrm{D} 3$ & 5.64 & 2.30 \\
\hline & & $I_{1}$ of $\mathrm{D} 4$ & 8.11 & 0.28 \\
\hline & & $T_{1}$ of D5 & 9.01 & 0.03 \\
\hline & & $\phi$ & 2.23 & 0.03 \\
\hline & Black & $I_{1}$ of D5 & 0.17 & 15.65 \\
\hline & \multirow{8}{*}{ Pink } & $T_{2} l m$ & 4.40 & 5.88 \\
\hline & & $T_{1} l m$ & 6.18 & 5.64 \\
\hline & & $I_{2}$ of $\mathrm{D} 3$ & 8.22 & 0.28 \\
\hline & & $I_{2}$ of D4 & 8.96 & 0.02 \\
\hline & & $T_{2}$ of D5 & 8.19 & 0.65 \\
\hline & & $I_{2}$ of D5 & 7.92 & 1.30 \\
\hline & & $T_{1}$ of D6 & 5.60 & 1.85 \\
\hline & & $I_{1}$ of D6 & 6.31 & 5.08 \\
\hline & \multirow{4}{*}{ Blue } & $T_{1}$ of D3 & 0.03 & 17.61 \\
\hline & & $T_{2}$ of D3 & 2.08 & 12.03 \\
\hline & & $T_{1}$ of $\mathrm{D} 4$ & 0.35 & 15.14 \\
\hline & & $T_{2}$ of D4 & 1.84 & 11.41 \\
\hline \multirow{17}{*}{ Native } & \multirow{3}{*}{ Green } & $T_{2}$ of N3 & 9.90 & 1.20 \\
\hline & & $T_{1}$ of $\mathrm{N} 4$ & 7.34 & 1.47 \\
\hline & & $T_{1}$ of N5 & 8.07 & 2.58 \\
\hline & \multirow{5}{*}{ Red } & $\phi$ & 1.86 & 4.51 \\
\hline & & $T_{2}$ of N2 & 4.63 & 10.05 \\
\hline & & $T_{1}$ of $\mathrm{N} 3$ & 1.99 & 12.35 \\
\hline & & $T_{2}$ of $\mathrm{N} 4$ & 2.98 & 10.30 \\
\hline & & $I_{1}$ of $\mathrm{N} 4$ & 2.87 & 10.81 \\
\hline & \multirow{5}{*}{ Black } & $T_{1} l m$ & 3.51 & 11.30 \\
\hline & & $T_{2} l m$ & 6.16 & 7.44 \\
\hline & & $I_{2}$ of $\mathrm{N} 4$ & 9.13 & 3.23 \\
\hline & & $I_{1}$ of $\mathrm{N} 5$ & 4.99 & 4.05 \\
\hline & & $I_{2}$ of N5 & 4.53 & 10.23 \\
\hline & \multirow{2}{*}{ Pink } & $I_{2}$ of $\mathrm{N} 3$ & 10.50 & 0.17 \\
\hline & & $T_{2}$ of N5 & 7.48 & 1.78 \\
\hline & \multirow{2}{*}{ Blue } & $I_{2}$ of $\mathrm{N} 2$ & 9.91 & 1.92 \\
\hline & & $I_{1}$ of $\mathrm{N} 3$ & 4.15 & 6.61 \\
\hline
\end{tabular}

Table S2 (Continued) 


\begin{tabular}{|c|c|c|c|c|}
\hline Saturation state & Coloristic group & $\begin{array}{l}\text { Original } \\
\text { Variable }\end{array}$ & $\begin{array}{c}\text { Contribution to } \\
\text { PC } 1(\%)\end{array}$ & $\begin{array}{c}\text { Contribution to } \\
\text { PC } 2(\%)\end{array}$ \\
\hline \multirow{24}{*}{ Saturated } & \multirow{8}{*}{ Green } & $T_{1} l m$ & 4.77 & 2.16 \\
\hline & & $T_{2} l m$ & 6.89 & 0.66 \\
\hline & & $T_{2}$ of $\mathrm{S} 3$ & 5.39 & 3.56 \\
\hline & & $I_{2}$ of $\mathrm{S} 3$ & 6.55 & 1.29 \\
\hline & & $T_{1}$ of $\mathrm{S} 4$ & 6.81 & 0.23 \\
\hline & & $I_{1}$ of $S 5$ & 4.95 & 0.00 \\
\hline & & $T_{2}$ of $\mathrm{S} 5$ & 0.80 & 4.44 \\
\hline & & $I_{2}$ of $\mathrm{S} 5$ & 2.27 & 4.12 \\
\hline & \multirow{7}{*}{ Pink } & $T_{2}$ of $\mathrm{S} 1$ & 6.40 & 0.57 \\
\hline & & $I_{2}$ of $\mathrm{S} 1$ & 6.62 & 1.20 \\
\hline & & $I_{1}$ of $\mathrm{S} 2$ & 4.56 & 0.70 \\
\hline & & $T_{2}$ of $\mathrm{S} 4$ & 7.18 & 0.07 \\
\hline & & $I_{2}$ of $\mathrm{S} 4$ & 6.65 & 0.72 \\
\hline & & $T_{1}$ of $\mathrm{S} 6$ & 2.82 & 3.72 \\
\hline & & $I_{1}$ of $\mathrm{S} 6$ & 2.25 & 4.15 \\
\hline & \multirow{4}{*}{ Orange } & $T_{1}$ of $\mathrm{S} 1$ & 1.21 & 11.75 \\
\hline & & $T_{1}$ of $\mathrm{S} 2$ & 2.19 & 9.12 \\
\hline & & $I_{2}$ of $\mathrm{S} 2$ & 0.06 & 13.95 \\
\hline & & $I_{1}$ of $S 4$ & 0.18 & 13.72 \\
\hline & \multirow{5}{*}{ Blue } & $I_{1}$ of $\mathrm{S} 1$ & 0.47 & 1.48 \\
\hline & & $T_{1}$ of $\mathrm{S} 3$ & 4.03 & 6.25 \\
\hline & & $I_{1}$ of $S 3$ & 4.83 & 4.68 \\
\hline & & $T_{1}$ of $\mathrm{S} 5$ & 1.44 & 10.38 \\
\hline & & $\phi$ & 3.68 & 0.83 \\
\hline \multirow{19}{*}{ Differential } & \multirow{7}{*}{ Green } & $T_{1} l m$ & 7.52 & 3.01 \\
\hline & & $T_{2} l m$ & 7.62 & 2.70 \\
\hline & & $T_{2}$ of SD2 & 8.91 & 0.03 \\
\hline & & $T_{2}$ of SD3 & 5.64 & 0.26 \\
\hline & & $I_{2}$ of SD3 & 7.74 & 2.47 \\
\hline & & $I_{2}$ of SD4 & 8.11 & 1.69 \\
\hline & & $\phi$ & 4.89 & 1.85 \\
\hline & \multirow{4}{*}{ Red } & $T_{2}$ of SD1 & 6.42 & 5.30 \\
\hline & & $T_{1}$ of SD3 & 2.34 & 8.05 \\
\hline & & $T_{1}$ of SD4 & 3.75 & 10.96 \\
\hline & & $T_{2}$ of SD4 & 3.07 & 12.32 \\
\hline & \multirow{2}{*}{ Black } & $T_{1}$ of SD2 & 0.08 & 11.63 \\
\hline & & $I_{1}$ of SD3 & 0.00 & 17.80 \\
\hline & \multirow{5}{*}{ Pink } & $T_{1}$ of SD1 & 8.94 & 0.18 \\
\hline & & $I_{1}$ of SD1 & 3.91 & 8.39 \\
\hline & & $I_{2}$ of SD1 & 7.59 & 2.94 \\
\hline & & $I_{1}$ of SD2 & 2.97 & 0.15 \\
\hline & & $I_{2}$ of SD2 & 7.46 & 0.04 \\
\hline & Orange & $I_{1}$ of SD4 & 3.04 & 10.24 \\
\hline
\end{tabular}




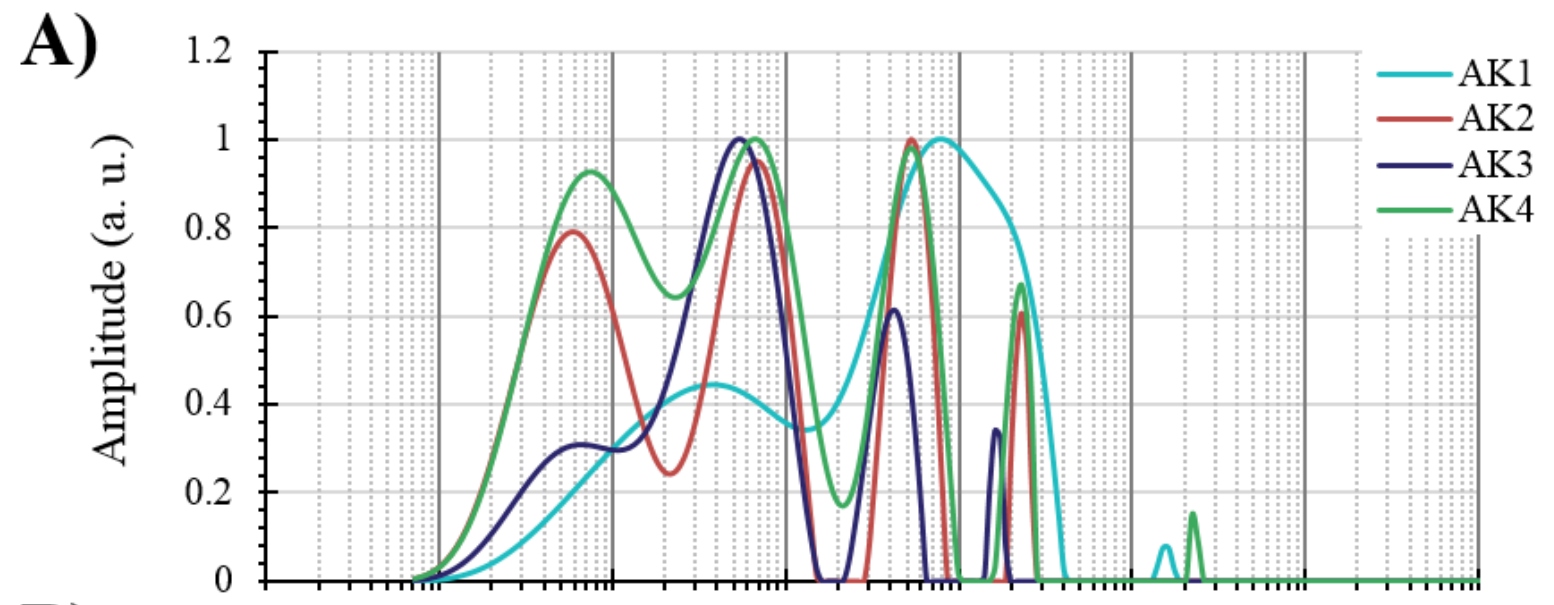

B)
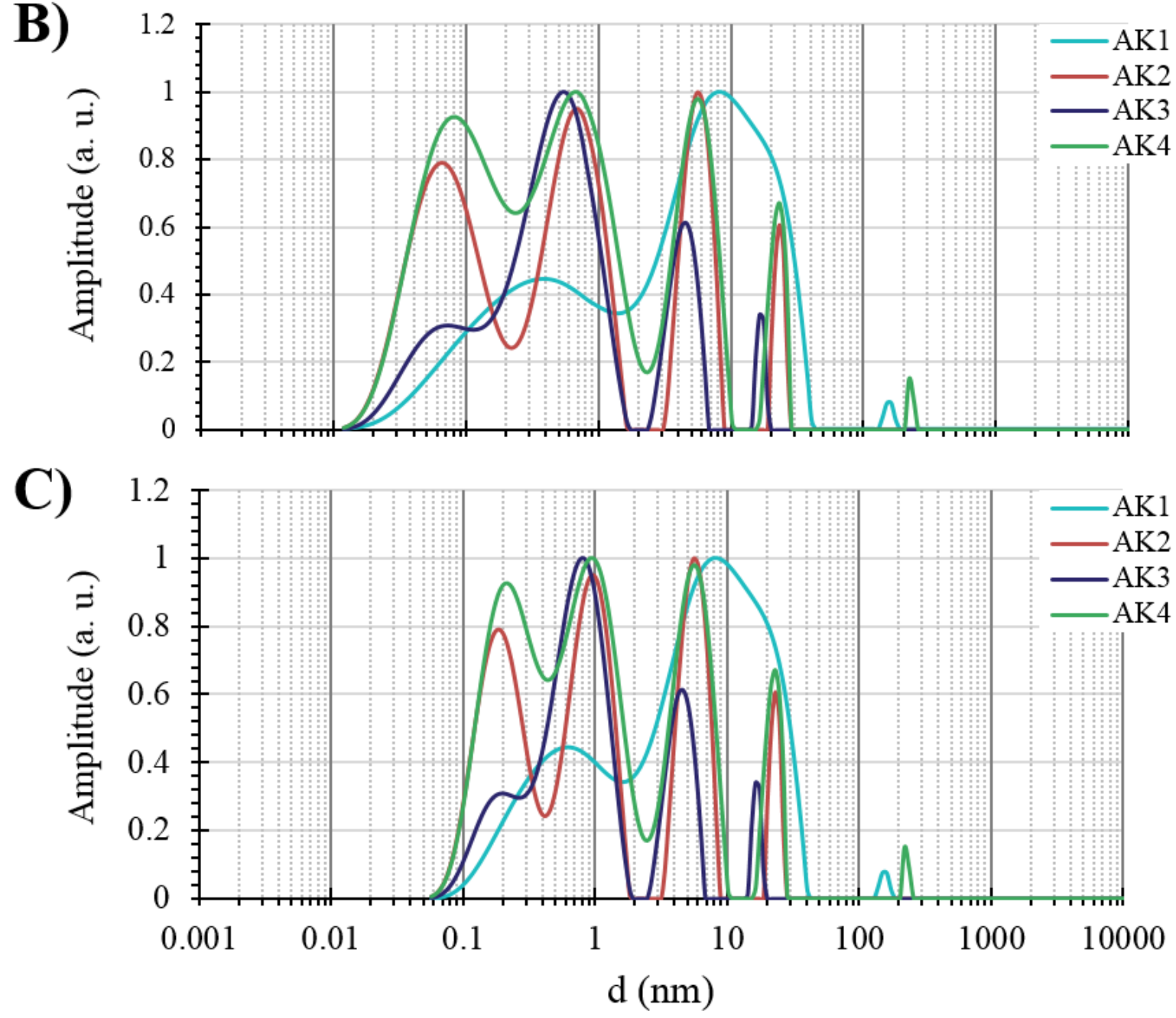

Figure S1. Pore Size Distribution (PSD) determined from 1D- $T_{2}$ distributions of saturated samples assuming that they are composed of $100 \% \mathrm{SiO}_{2}$. A) PSD assuming the absence of diffusion (linear relationship between $T_{2}$ surface and pore diameter, d); B PSD with diffusion taken into account considering $D$ changes from $4.5 \cdot 10^{-11} \mathrm{~m}^{2} / \mathrm{s}$ (for pores with $d<0.6 \mathrm{~nm}$ ) to $D_{0}=2.3 \cdot 10^{-9} \mathrm{~m}^{2} / \mathrm{s}$. C) PSD with diffusion taken into account using diffusion coefficient for bulk water $D_{0}=2.3 \cdot 10^{-9} \mathrm{~m}^{2} / \mathrm{s}$ in the whole range pore size. 